\title{
Protein I: Structure, Function, and Genetics
}

\author{
RALPH C. JUDD \\ Division of Biological Sciences, University of Montana, Missoula, Montana 59812
}

The study of the major outer membrane $(\mathrm{OM})$ protein, protein I (PI), of Neisseria gonorrhoeae has proven to be as fascinating, and as frustrating, as every other aspect of this remarkable bacterium. However, intensive studies over the last few years have provided significant insight into the structure, function, and genetics of this abundant, surfaceexposed porin protein. There are two forms of PI, which share up to $80 \%$ homology. The diversity of the exposed portion of the molecules among strains presents an everchanging immunogenic and antigenic dilemma to the reinfected host. Yet, it is the variability of the PI surface epitopes that has provided a precise method of serotyping $N$. gonorrhoeae, making it possible to monitor the prevalance and spread of strains within the host population and correlate functional differences between strains with PI structural types.

Recent successes in cloning and sequencing of both PI structural subclasses have already contributed to our understanding of the mechanism(s) whereby $N$. gonorrhoeae generates PI structural diversity. Continued investigation is needed to clarify the relationship between PI type and disseminated disease, resistance to serum killing, auxotypic requirements, interaction with host cells, and resistance to antibiotics. Observations regarding the ability of PI to interact with eucaryotic membranes suggest a role for PI in the pathogenesis of $N$. gonorrhoeae, whereas immune responsiveness of patients to PI points to the possibility of a PI vaccine. Clearly, at the molecular level, PI represents all the mystery and intrigue that $N$. gonorrhoeae presents at the organism level. Certainly, much remains to be learned before we have a complete picture of the structure, function, and genetics of PI.

\section{STRUCTURE}

PI (73) is known to exist in two structurally related forms, designated subclass PIA and subclass PIB (61), which have different orientations in the OM $(2,4)$. A given strain or $N$. gonorrhoeae expresses a single, invariant PI of one of the other subclass, which accounts for up to $60 \%$ of the protein in the OM (36), whether grown aerobically or anaerobically (16). There is significant structural variation within the subclasses, resulting in proteins of different apparent molecular mass $(52,72)$, different isoelectric points (with some as low as 5.5, but most close to 8.0) (3), and unique immunological reactivities $(6,45,61-63,75)$. PIAs tend to be smaller than PIBs, ranging in apparent molecular mass from about 34 to 36.5 kilodaltons $(\mathrm{kDa})$, whereas PIBs range from about 36 to $38 \mathrm{kDa}(38,52,72,73)$ (Fig. 1). Regardless of subclass, PIs appear to associate as trimeric porins which form hydrophilic channels through the OM $(3,19,51,78)$. Proteins of both subclasses show immunological variation $(6,45,61-63$, $75)$, which tends to be localized in surface-exposed portions of the molecules $(13,40,42,44,46,75)$. PIs also interact with other OM components, such as protein III (PIII) $(55,74)$ and lipooligosaccharide (LOS) (31), to form complex OM structures.

The amino acid sequences of a representative PIA (strain
FA19) (14) and two PIBs (strains R10 [23] and MS11 [13]) are known. PIA and PIB have identical 19-amino-acid leader sequences which are cleaved to produce the functional protein $(13,14,23)$. There is 65 to $80 \%$ homology between PIA and amino acid sequences of the two PIBs, confirming similarities previously observed by peptide mapping $(2,39$, $40,61,72$ ). Peptide mapping studies of PIAs and PIBs and sequence data for two PIBs (13) indicate that there is a higher degree of homology within the subclasses $(2,44,61$, 72). The predicted molecular masses from the deoxyribonucleic acid (DNA) sequences are about $34 \mathrm{kDa}$ for the PIA and 35.5 to $36 \mathrm{kDa}$ for the PIBs. These masses are remarkably close to the apparent molecular masses derived by sodium dodecyl sulfate-polyacrylamide gel electrophoresis and are consistent with the masses of Escherichia coli porin proteins $(14,20,23)$. Additionally, the PI sequences reveal an absence of long hydrophobic stretches and a lack of cysteine, and they have about $23 \%$ sequence homology with E. coli trimeric porins (23). Hydropathy patterns of the predicted PI sequences are also consistent with patterns of E. coli $\mathrm{OmpC}$ and $\mathrm{OmpF}$ porins (14), providing evidence that PI molecules act as porin proteins, forming hydrophilic channels across the $\operatorname{OM}(3,19,51,78)$.

Sequence differences between the PIA and PIB subclasses result in different orientations of the PIs in the OM (Fig. 2). PIAs are oriented in the OM in such a manner that they have a relatively small portion ( 15 to 20 amino acids) of the protein exposed on the bacterial surface $(2,4,42,44,68)$. PIBs traverse the membrane at least twice, having, perhaps, both termini embedded in the $\mathrm{OM}(2,4,68)$. Thus, PIAs are resistant to in situ proteolysis by trypsin and $\alpha$-chymotrypsin $(2,4,44,68)$, with only a short portion of the molecule being susceptible to cleavage by proteinase $\mathrm{K}$. Cleavage of purified PIAs from two strains of $N$. gonorrhoeae with leucine aminopeptidase, followed by immunoblot analysis, indicated that the N-terminus is the exposed portion of PIAs (42). A very recent study (13), in which shuttle mutagenesis was used to introduce a selectable marker near the PI gene, used transformation to locate surface epitopes of PIA and PIB in PIA-PIB hybrids. This study confirmed the N-terminal exposure of PIA, but suggested that there may be C-terminal exposure as well.

PIBs are very susceptible to in situ cleavage by exogenous proteases such as trypsin, $\alpha$-chymotrypsin, and proteinase $\mathrm{K}$ and by neutrophil proteases such as elastase and cathepsin $G$ (W. M. Shafer, personal communication), which cleave a central portion of the molecule, leaving two membranebound fragments $(2,4,44)$. Cleavage of purified PIBs with $\mathrm{CNBr}$ (76) and endopeptidases (21), followed by immunoblot analysis, demonstrated that the central portion of PIB is the surface-exposed portion of the molecule. Analysis of PIAPIB hybrids suggested that a portion of the $\mathrm{N}$ terminus may also be exposed in PIBs (13). The portions of the PIs that are exposed on the surface tend to be variable $(13,40,42,44,46$, 75) and possess epitopes which allow for immunological classification of strains based on the structural variation within the PIA and PIB subclasses $(6,46,61-63,75)$. 


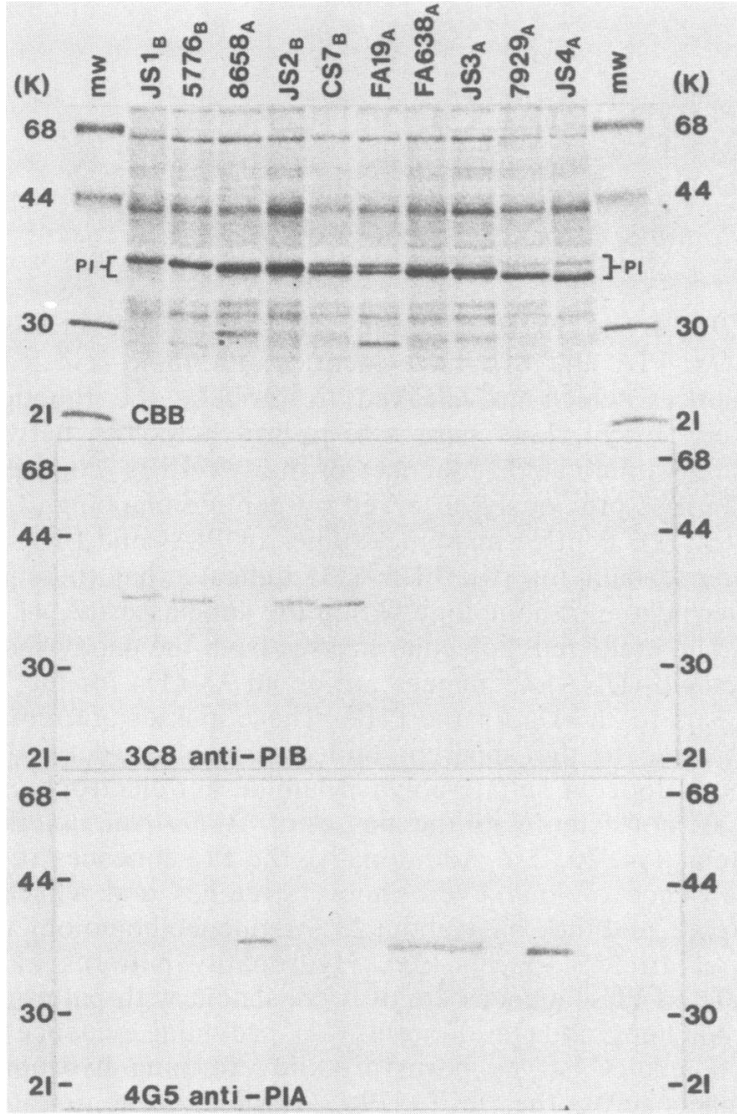

FIG. 1. Separation of whole-cell lysates of $N$. gonorrhoeae JS1, 5776, 8658, JS2, CS7, FA19, FA638, JS3, 7929, and JS4 by sodium dodecyl sulfate-polyacrylamide gel electrophoresis in a $12.5 \%$ gel. The top panel is the central portion of a Coomassie brilliant blue (CBB)-stained gel which shows the range of apparent molecular masses of PI. The apparent molecular masses, expressed in kilodaltons $(\mathrm{K})$, of the PI of each strain, as determined by comparison with the Bio-Rad low-molecular-weight markers (mw) are as follows: JS1, $37.7 \mathrm{kDa}$; 5776, $36.9 \mathrm{kDa}$; 8658, $37.3 \mathrm{kDa}$; JS2, 36.3 kDa; CS7, $35.7 \mathrm{kDa}$; FA19, 35.7 kDa; FA638, $35.7 \mathrm{kDa}$; JS3 $35.7 \mathrm{kDa} ; 7929$, $35.2 \mathrm{kDa}$; and JS4, $34.6 \mathrm{kDa}$. The middle panel is an immunoblot using the PIB-specific 3C8 MAb (75), and the bottom panel is an immunoblot using the PIA-specific 4G5 MAb (75). Both blots were probed with anti-mouse IgG-horseradish peroxidase. The PI subclass of each strain, as determined by ${ }^{125}$ I-labeled peptide mapping (42), is given as a subscript to each strain designation. Note that although the PIBs tend to be larger than the PIAs, there is considerable overlap in their apparent molecular masses. Also note that not all PIs bind these widely reactive anti-PI MAbs (e.g., strains JS3 and JS4), necessitating further analyses to determine the PI subclass of these nonreactive strains.

Initial efforts to serotype $N$. gonorrhoeae involved the use of antisera raised against OM vesicles (36). PI was a dominant antigen in these vesicles $(36,52)$, indicating that it might be useful in serotype analyses. Sandstrom and Danielsson (63), using absorbed polyclonal antisera in coagglutination assays, were able to separate $N$. gonorrhoeae into three serogroups designated WI, WII, and WIII. A second method of serogrouping, involving the use of anti-PI antibodies in an enzyme-linked immunosorbent assay, was developed by Buchanan and Hildebrandt (6). This system divided gonococci into nine serotypes. Further studies showed that both serogrouping systems correlated with the PI subclass: the WI strains and serogroup 1 to 3 have a PIA, and the WII and
WIII strains and serogroups 4 to 9 have a PIB $(61,63)$. A series of PI-specific monoclonal antibodies (MAbs) have since been produced (Fig. 1) which react with different epitopes on or near the surface-exposed portion of the PI molecules $(46,75)$. On the basis of the reactivity patterns to these "banks" of PIA- or PIB-specific MAbs in coagglutination assays, systems of serotyping have been developed that classify strains into serovariants, or serovars. Thus, strains of $N$. gonorrhoeae can be described by their PI subclass and the reactivity of the PI with the serovar MAbs (e.g., PIA-1 indicates that this strain has a PIA that reacts with all six of the serovar MAbs) $(46,65,75)$. The large number of serovar patterns demonstrates the wide structural variation in or around the surface-exposed regions of the PIs $(45,46,75)$. Exposure analyses have confirmed the structural variability of the surface-exposed regions of the PIs $(21,40,42,44,76)$.

Primary structural differences are not the only factors affecting PI structure in the OM. PI molecules interact to form trimeric porin structures $(3,51)$. PIII also interacts with $\mathrm{PI}$ in the $\mathrm{OM}$ in a ratio of three PIII molecules to one PI molecule, forming a complex that can be chemically crosslinked (55). Swanson et al. (74) confirmed an in situ association of PI and PIII by demonstrating that anti-PIII MAb coprecipitated PI. PIII may therefore participate in the formation, stabilization, and/or operation of the trimeric PI pore. A noncovalent association between LOS and PI has also been demonstrated (31). Although the nature of this association is not known, variation of LOS structure does correlate with differences in PI exposure in strains of $N$. gonorrhoeae having structurally identical PIAs or PIBs (R. C. Judd and W. M. Shafer, Mol. Microbiol., in press). Recent studies have demonstrated that PI is associated with peptidoglycan (PG) (S. A. Hill, Ph.D. thesis, University of Montana, Missoula, 1987), perhaps serving to anchor the $\mathrm{OM}$ to PG at critical sites. Neither protein IIs, pili, nor $\mathrm{H} .8$ antigen appear to interact directly with PI in the OM $(32,60)$. A recent study by Robinson et al. (60) demonstrated that the availability of PI to bind PI-specific MAb and polyclonal antibody in intact cells varied extensively, even within the same culture. This raises the possibility that structurally identical PIs do not have the same orientation in all cells; that PI is not expressed in all cells; or that some other, as yet undescribed, interaction between PI and another OM component(s) is occurring differently in different cells (60).

\section{FUNCTION}

The known function of PI is to form hydrophilic pores across the OM (porin) $(3,19,51)$. The porin function of PI is clearly necessary for the survival of the bacterium, allowing nutrients to penetrate into the cell and waste materials to exit. Other possible cellular functions of PI have been suggested, such as translocation into recipient membranes $(3,49)$ and association with PG (Hill, Ph.D. thesis). PI subclass has been associated with such traits as serum resistance $(12,29,38,57)$, resistance to antibiotics $(1,8,33$, $35,59)$, auxotype $(5,24,47,54,64)$, and expression of type 1 or type 2 immunoglobulin A1 (IgA1) protease (54). The role of $\mathrm{PI}$ in pathogenesis remains elusive, but the PI subclass has been associated with certain clinical states such as disseminated gonococcal infection and localized mucosal disease (5, $9,50,54,56,64)$.

The porin activity of PIs has been investigated by analyzing their ability to conduct electric currents when placed in lipid bilayers $(3,49,51,78)$. PIs inserted into artificial membrane bilayers conducted current in bursts, indicating 


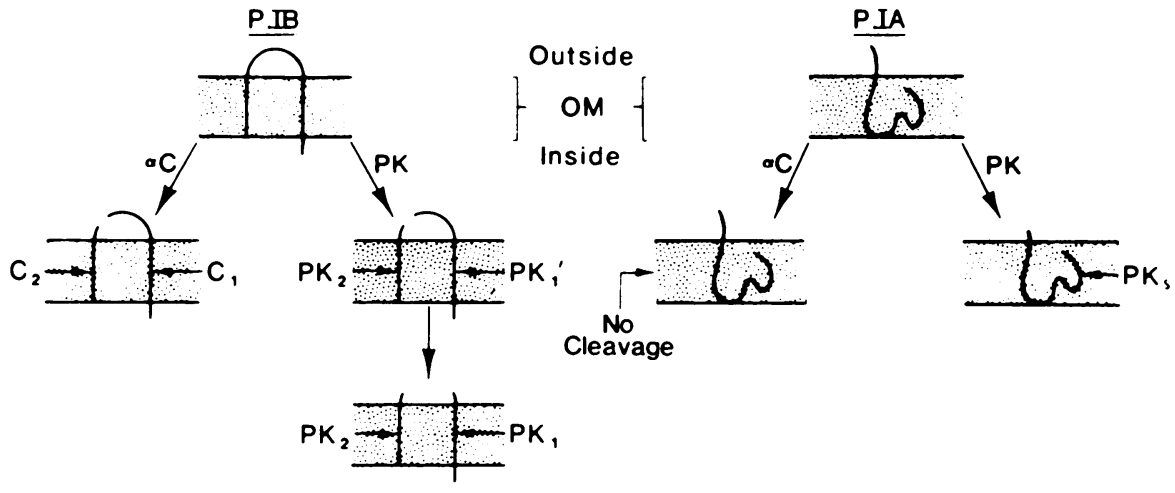

FIG. 2. Model of PIB and PIA in OMs of $N$. gonorrhoecle based on in situ cleavage by $\alpha$-chymotrypsin $(\alpha \mathrm{C})$ or proteinase K (PK). The PIs were cleaved to yield the fragments shown in this model. $\mathrm{C}_{1}, \mathrm{C}_{2}, \mathrm{PK}_{1}{ }^{\prime}$, which is further cleaved to produce the $\mathrm{PK}_{1}$ fragment, and $\mathrm{PK}_{2}$ are produced when PIB-bearing strains are treated with $\alpha$-chymotrypsin proteinase $\mathrm{K}$. The PK, fragment is generated when PIA-bearing strains are treated with proteinase K. PIAs are resistant to in situ cleavage by $\alpha$-chymotrypsin and trypsin. On the basis of these cleavage patterns, PIB has a central portion of the molecule exposed on the surface, with both termini embedded in the membrane, whereas PIAs have a short portion of the $\mathrm{N}$ terminus (42) exposed on the bacterial surface. Reproduced from Infection and Immunity (2) with permission of the publisher.

the pores existed in two states, open or closed $(3,49)$. Moreover, gonococcal PIs showed incremental voltage gating of current across a lipid bilayer in a manner characteristic of trimeric porins $(20,51)$. Thus, PIs appear to be porins with three PI molecules combining to form hydrophilic channels. through the OM (Fig. 3). The diameter of the pore has been estimated to be $2.5 \mathrm{~nm}(19)$, with an anion-selective channel ranging in $\mathrm{Cl}^{-} / \mathrm{K}^{+}$selectivity from $6: 1$ (for PIBs) to $3: 1$ (for PIAs) $(3,78)$.

Further studies with lipid bilayers have indicated that gonococcal PIs spontaneously insert into these membranes in an inverted manner $(3,49)$. The rate of insertion of $N$. gonorrhoeae PIs was lower for PIBs ( 5 to 10 pores per $h$ ) than for PIAs (100 pores per $h$ ) when $10^{6}$ organisms were placed in the test system. In comparison, Neisseria sicca did not transfer porin function to the bilayer, even when $10^{9}$ organisms were used, whereas $10^{6}$ organisms of Neisseria meningitidis transferred up to 1,500 pores per $h(3,49)$. Interestingly, gonococcal strains isolated from patients with disseminated disease had greater pore-forming activity than did strains isolated from mucosal sites (3), perhaps reflecting the observation that 80 to $90 \%$ of disseminated gonococcal infection isolates express the PIA subclass. It has been demonstrated that PI can be inserted into erythrocytes (3) and that transfer is facilitated when the recipient membrane is more fluid than the bacterial OM (3). The effect of this transfer on pathogenesis is unclear. It has been shown that neutrophils pretreated with purified PI had a decreased ability to exocytose granules and, in response to stimulation with $N$-formyl-Met-Leu-Phe, failed to increase their surface area and did not aggregate as well as control cells (25). PI has also been shown to bind calmodulin (3), a eucaryoticcell-regulatory molecule. The effect of these activities on pathogenesis remains unclear, but is seems reasonable that PI mediates important events in host cells that contribute to bacterial survival and pathogenesis.

$N$. gonorrhoeae lacks a protein analogous to Braun's lipoprotein found in E. coli (26). Recently, PI has been shown to be one of several PG-associated proteins (30), suggesting that PI may help bind the OM to PG. This is supported by the observation that PI binds lectins that are specific for sugars found in gonococcal PG (Hill, Ph.D. thesis). Moreover, antibody raised against highly purified PIB (R.C. Judd, Abstr. Third Biannual UA/UC Conf. Patho- genic Bacteria, abstr. no. 5, p. 1) cross-reacted extensively with several other PG-associated proteins, while antibody made to a purified $60-\mathrm{kDa}$ PG-associated protein reacts with PI, indicating that PI shares epitopes, probably of PG origin, with these molecules.

Protein I has been associated with several traits that are important to disease. The availability of serotyping reagents $(46,75)$ has made it possible to correlate PI subclass with many characteristics of the organism as well as the nature of the infection caused by a particular isolate. PIA has been associated with resistance to killing by normal human serum $(29,38,57)$. As with most things gonococcal, the association is not absolute. A recent study comparing susceptibility to killing by normal human serum in transformant strains which have identical PIAs or PIBs in differing LOS and H.8 antigen backgrounds demonstrated that PI subclass does not account for serum resistance (R. K. Pettit, J. C. Szuba, and R. C. Judd, unpublished data), confirming that other bacterial components must play a role in resistance $(11,12$, 69-71).

There does appear to be a relationship between PI subclass and antibiotic resistance. Several studies indicate that resistance to rifampin (8), thiamphenicol (8), ampicillin (59), and penicillin $(59,67)$ correlates strongly with the PIB subclass. Correlations between PI subclass and antibiotic resistance are somewhat dependent on geographical location (33, 35, 59), and both PIA- and PIB-bearing strains are capable of plasmid-and chromosome-mediated resistance to antibiotics. There is a consistent correlation between the arginine ${ }^{-}$hypoxanthine ${ }^{-}$uracil $^{-}\left(\mathrm{AHU}^{-}\right)$auxotype and PIA $(5,24,47,54,64)$. Other auxotypes do not correlate as strongly with a particular PI subclass. Therefore, serotyping schemes have been developed which combine the PI serovar and auxotype to classify gonococcal isolates $(24,45)$.

Another association regarding PI subclass is the production of type $1 \mathrm{IgA} 1$ protease, which is produced predominantly by $\mathrm{AHU}^{-}$, PIA-bearing strains, and type $2 \operatorname{IgA} 1$ protease, which is produced by many other auxotypes and serovars (54). The $\mathrm{AHU}^{-}$auxotype and PIA subclass do correlate with the ability to cause disseminated infection $(5$, $9,47,50,54,56,64)$; the majority $(>85 \%)$ of blood isolates possess the PIA subclass of PI, and about $60 \%$ are $\mathrm{AHU}^{-}$ $(47,56)$. Mucosal isolates tend $(>60 \%)$ to possess the PIB subclass of PI. It is important to note that both PIA- and 


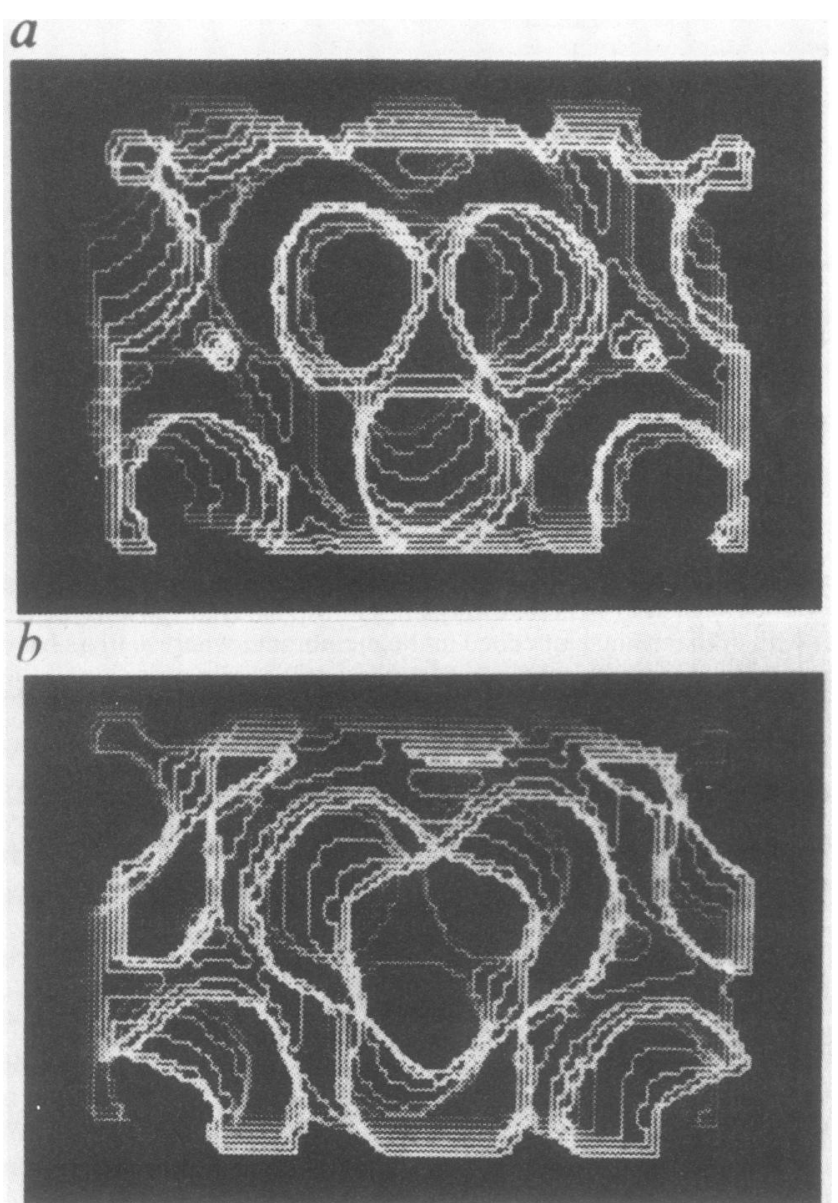

FIG. 3. Three-dimensional reconstruction of the small hexagonal form of a trimeric porin formed by $E$. coli matrix protein $(\mathrm{OmpF})$ in reconstituted phospholipid membranes as viewed externally (a) and internally (b). Conductance measurements demonstrated a series of voltage-dependent openings and closings indicative of a trimeric pore as depicted in panel a. The three pores, which open and close independently, merge to form a single channel on the periplasmic side to the membrane (panel b). Conductance experiments on PI of $N$. gonorrhoeae inserted into lipid membranes demonstrated similar voltage-dependent gating data (51), indicating that PI forms trimeric pores analogous to those formed by the $E$. coli matrix protein as seen here. Reprinted from Nature (London) (20) with permission of the publisher.

PIB-bearing strains have been isolated from blood, joints, and mucosal sites $(50,56)$.

The host immune response to PI depends on previous immune status $(28,66)$ and site $(48,56)$ and duration $(22,28$, 79) of infection. Several studies have demonstrated that normal human serum contains anti-PI antibody. In one study, normal human serum was shown to specifically inhibit anti-PI monoclonal antibody binding. This inhibiting antibody in normal human serum was opsonic (66). In a pre- and posturethral infection study, immunoblot analysis showed that 12 of 13 men possessed preformed anti-gonococcal antibody, some directed against PI, perhaps being crossreactive antibody from previous exposure to $N$. meningitidis or other gram-negative organisms (28). Following infection, nine men showed a temporal increase in antibody levels against gonococcal antigens, including PI (28). A study comparing antibodies in serum and vaginal fluid from women with disseminated gonococcal infection, peritoneal inflam- matory disease, and uncomplicated mucosal infections indicated that both IgG and IgA in vaginal fluid reacted more strongly with PI of the infecting strain of $N$. gonorrhoeae than did serum antibody (48). Radioimmunoprecipitation studies of serum from sexual partners suffering from localized mucosal infections demonstrated that both men and women produced anti-PI antibody in their sera in response to infection (79).

The role of anti-PI antibody in infection is unknown. However, the possibility that anti-PI antibody is important in limiting infection is supported by the observation that antiPIII antibody blocked the bactericidal activity of anti-PI antibody in convalescent-phase serum (58), reflecting the close association of PI and PIII in the OM. When anti-PIII antibodies were removed from the serum, bactericidal activity was restored (58), indicating that anti-PI antibody in patient serum can kill $N$. gonorrhoeae.

Many anti-PIA and anti-PIB MAbs are able to activate the classical complement cascade, resulting in cell killing (27, $38,77)$. The juxtaposition of the exposed PIA epitopes and other OM components seems to be critical in determining whether a particular MAb will be bactericidal, since MAbs that activate equivalent amounts of complement and that bind equivalently to cells showed marked differences in their ability to kill $N$. gonorrhoeae (38). A similar situation appears to occur with anti-PIB MAbs (77). The difference in killing is related to the manner in which the activated complement is deposited on the bacterial surface $(37,38)$. Anti-PIA and anti-PIB MAbs have also been shown to be opsonic and are able to inhibit the invasion of $N$. gonorrhoeae into epithelial cells (27).

The ability of anti-PI antibody to kill $N$. gonorrhoeae, combined with the relative abundance of PIs, their universal expression, the apparent structural similarity between PIs within each subclass, their antigenic stability within a strain, and the presence of anti-PI antibody in the mucus and serum, even following uncomplicated mucosal infection, has encouraged the use of PI as a potential vaccine. Purified PIB has been used, unsuccessfully, in vaccine trials (Sexually Transmitted Diseases 1986 National Institute of Allergy and Infectious Diseases Study Group Summary and Recommendations; K. K. Holmes, General Chairman; November 1987). In another study, recipients did show specific responses when injected with a PI preparation (F. Arminjon, M. Cadoz, S. A. Morse, J. P. Rock, and S. K. Sarafian, Abstr. Annu. Meet. Am. Soc. Microbiol. 1987, E92, p. 118). Attempts to improve the immunogenicity of PI have been made, especially by using liposomes as delivery vehicles (34). Such studies indicate that both PI-detergent complexes and PI-liposomes induce anti-PI antibodies but that PIliposomes elicit the larger primary response (34).

The immunodominant portion of the PI molecule appears to be the most exposed region $(13,40,42,46,75)$. Since this region is also the variable part of the PI molecule, several groups are attempting to identify conserved epitopes which are available to bind anti-PI antibody. One approach is to use MAbs to locate such regions (77). Another approach is to use cloned PI genes to synthesize peptides of PI $(13,14,23)$, whereas others are using peptides generated by cleaving purified PIs and recovering surface-exposed fragments for immunogenicity and antigenicity studies $(41,43,76)$.

\section{GENETICS}

The majority of information about the genetics of PI has come from transformation studies (12). As yet, no mutant 


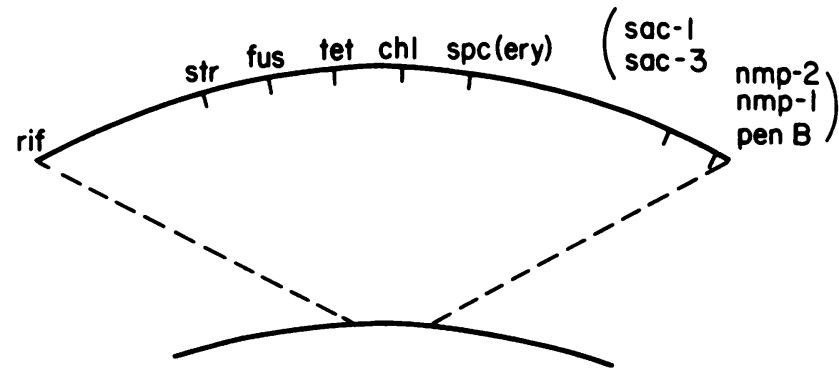

FIG. 4. Linked chromosomal genes for antibiotic resistance (rif, rifampin; str, streptomycin; fus, fusidic acid; tet, tetracycline; chl, chloramphenicol; spc, spectinomycin; ery, erythromycin; penB, nonspecific resistance to penicillin, tetracycline, and chloramphenicol), resistance to serum killing by normal human serum (sac-1 and sac-3), and PI structure (nmp-1 and nmp-2). All loci were mapped by three-factor transformation crosses. Parentheses indicate uncertainties regarding the positions of closely linked markers. Reproduced from Annual Review of Microbiology (12) with permission of the publisher.

strains lacking PI have been found, nor have strains been developed which have mutations in a PI gene $(13,14,23)$. The availability of PI gene sequences for both PI subclasses $(13,14,23)$ may prove invaluable in the generation of PI mutants, providing much-needed information about the structure and function of PI genes and the PI molecule. Transformation, by using both PIA- and PIB-specific MAbs (17), and by using a selectable marker linked to PI genes (13), has already provided several strains of $N$. gonorrhoeae expressing PIA-PIB hybrids, making functional and immunological studies possible.

Transformation studies have identified genetic loci, designated $n m p$ (new membrane protein), that affect the apparent molecular mass of PI (10). Introduction of a particular $n m p$ results in the expression of a unique PI (e.g., $n m p-l$ results in the expression of a PIB-1, $n m p-3$ results in a PIB-9, $n m p-4$ results in a PIA-1, etc.) (17). The $n m p$ loci are very closely linked to loci that influence serum resistance (sac [serum antibody complement]) (11) and to the penB locus (which is probably identical to the nsr locus [nonspecific resistance] described by Bygdeman et al. [7]), which produces lowlevel, nonspecific resistance to penicillin, chloramphenicol, and tetracycline. The $n m p$ region is less closely linked to genes determining resistance to streptomycin (str) and spectinomycin (spc) and several other antibiotics (Fig. 4) (12). It now appears certain that $n m p$ are structural genes for PI (13). Hybridization studies with PIB gene probes suggest that the structural PI gene exists in a single copy in the genome (23). This observation was confirmed by Carbonetti et al. (13), who demonstrated that the PIA and PIB genes are alleles of the same gene.

Transformation usually results in the expression of the donor PI which has the $n m p$ locus linked to the penB locus (12), although occasionally the recipient PI is expressed (17). This verifies that the penB locus can be separated from $n m p$. In a study by Danielsson et al. (17), hybrid PIBs, which acquired unique serovars, were produced in about $6 \%$ of the transformants, in which the donor expressed PIB-1 and the recipient expressed a PIB-7, suggesting that recombination had occurred. A similar result was reported for PIA (15), when a transformant generated from a PIA donor and a PIB recipient expressed a PIA that had lost several of the parental PIA epitopes. Moreover, when PIB donor DNA was transformed into a PIA recipient, a single transformant expressed a hybrid PI which had epitopes of both the PIB and PIA molecules (17).

Such observations indicate that new PI molecules, expressing unique surface epitopes, can be generated by genetic exchange between different strains of $N$. gonorrhoeae. The occurrence of PIA-PIB hybrids is extremely rare in nature (46), but the diversity of PI serovars suggests that some form of natural recombination of PI genes does occur. A possible mechanism for in vivo genetic exchange comes from recent observations by Dorward and Judd (18) which demonstrated that naturally elaborated OM blebs of $N$. gonorrhoeae contain DNA. Further, it has been shown that blebs from strains of $N$. gonorrhoeae which possess the gene for penicillinase can transfer penicillin resistance to recipient, penicillin-susceptible strains with great efficiency in the presence of high levels of exogenous deoxyribonuclease (D. W. Dorward, C. F. Garon, and R. C. Judd, submitted for publication). Therefore, in vivo genetic exchange between coinfecting strains of gonococci might occur through blebmediated transfer of DNA. PI may form channels between the blebs (which have been shown to possess an abundance of PI molecules) and the recipient cells in a manner analogous to the inverted insertion of PI into eucaryotic cells (3, 49), allowing the DNA to pass from the bleb to the cell.

The close proximity of the $s a c-1$ and $s a c-3$ loci to the $n m p$ loci may, in an unknown manner, contribute to the relationship of serum resistance and the PIA subclass. The mechanism by which the $s a c-l$ locus influences serum resistance is unknown, but the $s a c-3$ locus apparently effects LOS structure (71). Both sac loci influence serum resistance independently of the $n m p$ loci, since the three loci are separable, and serum-resistant PIB-bearing organisms and serum-sensitive PIA-bearing organisms have been generated by transformation $(12,69)$. Recent reports of a $29-\mathrm{kDa}$ molecule that correlates with serum resistance and disseminated disease (53) may help elucidate the mechanism(s) of serum resistance and its relationship to PI expression.

The availability of the amino acid sequences for one PIA (14) and two PIBs $(13,23)$ offers the opportunity to greatly increase our knowledge of the gonococcal PI. Although the PI genes have not been cloned and expressed in a stable cell line (the PIB sequences were elucidated from clones expressing overlapping, truncated PIs, as was the PIA sequence, although an intact PIA was expressed in a shortlived clone), it may now be possible to generate mutations in PI that will greatly improve our understanding of the structure, function, and genetics of PI and hence the role PI in the physiology, pathology, and immunobiology of $N$. gonorrhoeae.

\section{ACKNOWLEDGMENTS}

I thank Robin Pettit for her assistance in the preparation of this manuscript, W. O. Granath and W. M. Shafer for their critical review of the manuscript, and the organizers of the Sixth International Conference on Pathogenic Neisseriae for their confidence. I also thank Osmar Barrera and J. Swanson; J. G. Cannon and P. F. Sparling; and A. Engel, A. Massalski, H. Schindler, D. L. Dorset, and $\mathbf{J}$. P. Rosenbusch for allowing me to use their figures in this manuscript.

\section{LITERATURE CITED}

1. Abeck, D., A. P. Johnson, and H. C. Korting. 1988. Characterization of penicillinase producing gonococci isolated in Munich, 1981-1986. Genitourin. Med. 64:3-6. 
2. Barrera, O., and J. Swanson. 1984. Proteins IA and IB exhibit different surface exposures and orientations in the outer membranes of Neisseria gonorrhoeae. Infect. Immun. 44:565-568.

3. Blake, M. S., and E. C. Gotschlich. 1987. Functional and immunogenic properties of pathogenic Neisseria surface proteins, p. 377-399. In M. Inouye (ed.), Bacterial membranes as model systems. John Wiley \& Sons, Inc., New York.

4. Blake, M. S., E. C. Gotschlich, and J. Swanson. 1981. Effect of proteolytic enzymes on the outer membrane proteins of Neisseria gonorrhoeae. Infect. Immun. 34:212-222.

5. Brunham, R. C., F. Plummer, L. Slaney, F. Rand, and W. DeWitt. 1985. Correlation of auxotype and protein I type with expression of disease due to Neisseria gonorrhoeae. J. Infect. Dis. 152:339-343.

6. Buchanan, T. M., and J. F. Hildebrandt. 1981. Antigen-specific serotyping of Neisseria gonorrhoeae: characterization based on the principal outer membrane protein. Infect. Immun. 32:985994.

7. Bygdeman, S., M. Blackman, D. Danielsson, and M. Norgren. 1982. Genetic linkage between serogroup specificity and antibiotic resistance in Neisseria gonorrhoeae. Acta Pathol. Microbiol. Immunol. Scand. Sect. B 90:243-250.

8. Bygdeman, S. M., P. A. Mårdh, and E. G. Sandstrom. 1984. Susceptibility of Neisseria gonorrhoeae to rifampicin and thiamphenicol: correlation with protein I antigenic determinants. Sex. Transm. Dis. 11:366-370.

9. Cannon, J. G., T. M. Buchanan, and P. F. Sparling. 1983. Confirmation of association of protein I serotype of Neisseria gonorrhoeae with ability to cause disseminated infection. Infect. Immun. 40:816-819.

10. Cannon, J. G., D. G. Klapper, E. Y. Blackman, and P. F. Sparling. 1980. Genetic locus (nmp-l) affecting the principal outer membrane protein of Neisseria gonorrhoeae. J. Bacteriol. 143:847-851.

11. Cannon, J. G., T. J. Lee, L. F. Guymon, and P. F. Sparling. 1981. Genetics of serum resistance in Neisseria gonorrhoeae: sac-1 genetic locus. Infect. Immun. 32:547-552.

12. Cannon, J. G., and P. F. Sparling. 1984. The Genetics of the gonococcus. Annu. Rev. Microbiol. 38:111-133.

13. Carbonetti, N. H., V. I. Simnad, H. S. Seifert, M. So, and P. F. Sparling. 1988. Genetics of protein I of Neisseria gonorrhoeae: construction of hybrid porins. Proc. Natl. Acad. Sci. USA 85:6841-6845.

14. Carbonetti, N. H., and P. F. Sparling. 1987. Molecular cloning and characterization of the structural gene for protein $I$, the major outer membrane protein of Neisseria gonorrhoeae. Proc. Natl. Acad. Sci. USA 84:9084-9088.

15. Catlin, B. W., and E. N. Shinners. 1985. Gonococcal protein I: dissection and linkage association of $n m p-1$, p. 123-129. In G. K. Schoolnik, G. F. Brooks, S. Falkow, C. E. Frasch, J. S. Knapp, J. A. McCutchan, and S. A. Morse (ed.), The pathogenic neisseriae. American Society for Microbiology, Washington, D.C.

16. Clark, V. L., L. A. Campbell, D. A. Palermo, T. M. Evans, and K. W. Klimpel. 1987. Induction and repression of outer membrane proteins by anaerobic growth of Neisseria gonorrhoeae. Infect. Immun. 55:1359-1364.

17. Danielsson, D., H. Faruki, D. Dyer, and P. F. Sparling. 1986. Recombination near the antibiotic resistance locus penB results in antigenic variation of gonococcal outer membrane protein I. Infect. Immun. 52:529-533.

18. Dorward, D. W., and R. C. Judd. 1988. The isolation and partial characterization of naturally-evolved outer membrane blebs of Neisseria gonorrhoeae, p. 349-356. In J. T. Poolman, H. C. Zarer, T. F. Meyer, J. E. Heckels, P. R. H. Makela, H. Smith, and E. C. Beuvery (ed.), Gonococci and meningococci. Kluwer Academic Publications, Dordrecht, The Netherlands.

19. Douglas, J. T., M. D. Lee, and H. Nikaido. 1981. Protein I of Neisseria gonorrhoeae outer membrane is a porin. FEMS Microbiol. Lett. 12:305-309.

20. Engel, A., A. Massalski, H. Schindler, D. L. Dorset, and J. P. Rosenbusch. 1985. Porin channel triplets merge into single outlets in Escherichia coli outer membranes. Nature (London)
317:643-645.

21. Fletcher, J. N., K. Zak, M. Virji, and J. E. Heckles. 1986. Monoclonal antibodies to gonococcal outer membrane protein I: location of a conserved epitope on protein IB. J. Gen. Microbiol. 132:1621-1629.

22. Fohn, M. J., T. A. Mietzner, T. W. Hubbard, S. A. Morse, and E. W. Hook III. 1987. Human immunoglobulin G antibody response to the major gonococcal iron-regulated protein. Infect. Immun. 55:3065-3069.

23. Gotschlich, E. C., M. E. Seiff, M. S. Blake, and M. Koomey, 1987. Porin protein of Neisseria gonorrhoeae: cloning and gene structure. Proc. Natl. Acad. Sci. USA 84:8135-8139.

24. Grunder, K., A. Baumgartner, P. K. Kohl, M. R. Tam, and J. S. Knapp. 1987. Classification of gonococcus: auxanologic and serologic aspects using monoclonal antibodies. Z. Hautkr. 62: 1086-1100.

25. Haines, K. A., L. Yeh, M. S. Blake, P. Cristello, H. Korchak, and G. Weissmann. 1988. Protein I, a translocatable ion channe from Neisseria gonorrhoeae, selectively inhibits exocytosis from human neutrophils without inhibiting $\mathrm{O}_{2}$ - generation. $\mathrm{J}$. Biol. Chem. 263:945-951.

26. Hebeler, B. H., and F. E. Young. 1976. Chemical composition and turnover of peptidoglycan in Neisseria gonorrhoeae. $\mathrm{J}$ Bacteriol. 126:1180-1185.

27. Heckels, J. E., M. Virji, K. Zak, and J. N. Fletcher. 1987. Immunobiology of gonococcal outer membrane protein I Antonie Van Leeuwenhoek J. Microbiol. 53:461-464.

28. Hicks, C. B., J. W. Boslego, and B. Brandt. 1987. Evidence of serum antibodies to Neisseria gonorrhoeae before gonococcal infection. J. Infect. Dis. 155:1276-1281.

29. Hildebrandt, J. F., L. W. Mayer, S. P. Wang, and T. M. Buchanan. 1978. Neisseria gonorrhoeae acquire a new principal outer-membrane protein when transformed to resistance to serum bactericidal activity. Infect. Immun. 20:267-272.

30. Hill, S. A., and R. C. Judd. 1988. Structural and immunological characterization of cell wall antigens in strains FA638 and CS7 of Neisseria gonorrhoeae, p. 373-382. In J. T. Poolman, H. C. Zarer, T. F. Meyer, J. E. Heckels, P. R. H. Makela, H. Smith, and E. C. Beuvery (ed.), Gonococci and meningococci. Kluwer Academic Publications, Dordrecht, The Netherlands.

31. Hitchcock, P. J. 1984. Analyses of gonococcal lipopolysaccharide in whole-cell lysates by sodium dodecyl sulfate-polyacrylamide gel electrophoresis: stable association of lipopolysaccharide with the major outer membrane protein (protein I) of Neisseria gonorrhoeae. Infect. Immun. 46:202-212.

32. Hitchcock, P. J., S. F. Hayes, L. W. Mayer, W. M. Shafer, and S. L. Tessier. 1985. Analyses of gonococcal H8 antigen. Surface location, inter- and intrastrain electrophoretic heterogeneity, and unusual two-dimensional electrophoretic characteristics. J. Exp. Med. 162:2017-2034.

33. Hook, E. W., F. N. Judson, K. K. Handsfield, J. M. Ehret, K. K. Holmes, and J. S. Knapp. 1987. Auxotype/serovar diversity and antimicrobial resistance of Neisseria gonorrhoeae in two midsized American cities. Sex. Transm. Dis. 14:141-146.

34. Jiskoot, W., T. Teerlink, M. M. Van Hoof, K. Bartels, V. Kanhai, D. J. Crommelin, and E. C. Beuvery. 1986. Immunogenic activity of gonococcal protein I in mice with three different lipoidal adjuvants delivered in liposomes and in complexes. Infect. Immun. 54:333-338.

35. Johnson, A. P., D. Abeck, R. A. Wall, and D. C. Nabey. 1987. Plasmid content, auxotype, and protein-I serovar of gonococci isolated in the Gambia. Epidemiol. Infect. 99:669-674.

36. Johnston, K. H., K. K. Holmes, and E. C. Gotschlich. 1976. The serological classification of Neisseria gonorrhoeae. I. Isolation of the outer membrane complex responsible for the serotypic specificity. J. Exp. Med. 143:741-758.

37. Joiner, K. A., K. A. Warren, E. J. Brown, J. Swanson, and M. M. Frank. 1983. Studies on the mechanism of bactericidal resistance to complement-mediated killing IV: C5b-9 forms high molecular weight complexes with bacterial outer-membrane constituents on serum-resistant but not serum-sensitive Neisseria gonorrhoeae. Infect. Immunol. 131:1443-1451.

38. Joiner, K. A., K. A. Warren, M. Tam, and M. M. Frank. 1985. 
Monoclonal antibodies directed against gonococcal protein 1 vary in bactericidal activity. J. Immunol. 134:3411-3419.

39. Judd, R. C. 1982 . ${ }^{125}$ I-peptide mapping of protein III isolated from four strains of Neisseria gonorrhoeae. Infect. Immun. 37:622-631.

40. Judd, R. C. 1982. Surface peptide mapping of protein I and protein III of four strains of Neisseria gonorrhoeae. Infect. Immun. 37:632-641.

41. Judd, R. C. $1983 .{ }^{125}$ I-labeled peptide mapping and high-performance liquid chromatography ${ }^{125}$ I-peptide separation of protein I of four strains of Neisseria gonorrhoeae. J. Liq. Chromatogr. 6:1421-1439.

42. Judd, R. C. 1986. Evidence for N-terminal exposure of the protein IA subclass of Neisseria gonorrhoeae protein I. Infect. Immun. 54:408-414.

43. Judd, R. C. 1987. Radioiodination and ${ }^{125}$ I-labeled peptide mapping of proteins on nitrocellulose membranes. Anal. Biochem. 160:306-315.

44. Judd, R. C., M. Tam, and K. Joiner. 1987. Characterization of protein I from serum-sensitive and serum-resistant transformants of Neisseria gonorrhoeae. Infect. Immun. 55:273-276.

45. Knapp, J. S., E. G. Sandstrom, and K. K. Holmes. 1985. Overview of epidemiological and clinical applications of auxotype/serovar classification of Neisseria gonorrhoeae, p. 6-12. In G. K. Schoolnik, G. F. Brooks, S. Falkow, C. E. Frasch, J. S. Knapp, J. A. McCutchan, and S. A. Morse (ed.), The pathogenic neisseriae. American Society for Microbiology, Washington, D.C.

46. Knapp, J. S., M. R. Tam, R. C. Nowinski, K. K. Holmes, and E. G. Sandstrom. 1984. Serological classification of Neisseria gonorrhoeae with use of monoclonal antibodies to gonococcal outer membrane protein I. J. Infect. Dis. 150:44-48.

47. Kohl, P. K., J. S. Knapp, H. Hofmann, K. Gruender, D. Petzoldt, M. R. Tam, and K. K. Holmes. 1986. Epidemiological analysis of Neisseria gonorrhoeae in the Federal Republic of Germany by auxotyping and serological classification using monoclonal antibodies. Genitourin. Med. 62:145-150.

48. Lammel, C. J., R. L. Sweet, P. A. Rice, J. S. Knapp, G. K. Schoolnik, D. C. Heilbron, and G. F. Brooks. 1985. Antibodyantigen specificity in the immune response to infection with Neisseria gonorrhoeae. J. Infect. Dis. 152:990-1001.

49. Lynch, E. C., M. S. Blake, E. C. Gotschlich, and A. Mauro. 1984. Studies on porins: spontaneously transferred from whole cells and from proteins of Neisseria gonorrhoeae and Neisseria meningitidis. Biophys. J. 45:104-107.

50. Martin, D., P. L. Turgeon, and L. G. Mathieu. 1986. Approximate molecular weight of envelope protein I and colony opacity of Neisseria gonorrhoeae strains isolated from patients with disseminated or localized infection. Sex. Transm. Dis. 13:71-75.

51. Mauro, A., M. S. Blake, and P. Labarca. 1988. Voltage gating of conductance in lipid bilayers induced by porins from outer membrane of Neisseria gonorrhoeae. Proc. Natl. Acad. Sci. USA 85:1071-1075.

52. McDade, R. L., Jr., and K. H. Johnston. 1980. Characterization of serologically dominant outer membrane proteins of Neisseria gonorrhoeae. J. Bacteriol. 141:1183-1191.

53. McShan, W. M., R. P. Williams, and R. A. Hull. 1987. A recombinant molecule from a disseminating strain of Neisseria gonorrhoeae that confers serum bacterial resistance. Infect. Immun. 55:3017-3022.

54. Mulks, M. H., and J. S. Knapp. 1987. Immunoglobulin A1 protease types of Neisseria gonorrhoeae and their relationship to auxotype and serovar. Infect. Immun. 55:931-936.

55. Newhall, W. J., W. D. Sawyer, and R. A. Haak. 1980. Crosslinking analysis of the outer membrane proteins of Neisseria gonorrhoeae. Infect. Immun. 28:785-791.

56. O'Brien, J. P., D. L. Goldenberg, and P. A. Rice. 1983. Disseminated gonococcal infection: a prospective analysis of 49 patients and a review of pathophysiology and immune mechanisms. Medicine 62:395-406.

57. Odum, L., T. M. Buchanan, and J. S. Knapp. 1987. Protein I serotype of serum-resistant versus serum-sensitive Neisseria gonorrhoeae strains. Acta Pathol. Microbiol. Immunol. Scand.
Sect. B 95:1-4.

58. Rice, P. A., H. E. Vayo, M. R. Tam, and M. S. Blake. 1986. Immunoglobulin $\mathrm{G}$ antibodies directed against protein III block killing of serum-resistant Neisseria gonorrhoeae by immune serum. J. Exp. Med. 164:1735-1748.

59. Rice, R. J., J. W. Biddle, Y. A. JeanLouis, W. E. DeWitt, J. H. Blount, and S. A. Morse. 1986. Chromosomally mediated resistance in Neisseria gonorrhoeae in the United States: results of surveillance and reporting, 1983-1984. J. Infect. Dis. 153:340345

60. Robinson, E. N., Jr., Z. A. McGee, T. M. Buchanan, M. S. Blake, and P. J. Hitchcock. 1987. Probing the surface of Neisseria gonorrhoeae: simultaneous localization of protein I and H.8 antigens. Infect. Immun. 55:1190-1197.

61. Sandstrom, E. G., K. C. S. Chen, and T. M. Buchanan. 1982. Serology of Neisseria gonorrhoeae: coagglutination serogroups WI and WII/WIII correspond to different outer membrane protein I molecules. Infect. Immun. 38:462-470.

62. Sandstrom, E. G., and D. Danielsson. 1980. Serology of Neisseria gonorrhoeae: classification by co-agglutination. Acta Pathol. Microbiol. Scand. Sect. B 88:27-38.

63. Sandstrom, E. G., J. S. Knapp, and T. M. Buchanan. 1982. Serology of Neisseria gonorrhoeae: W-antigen serogrouping by coagglutination and protein I serotyping by enzyme-linked immunosorbent assay both detect protein I antigens. Infect. Immun. 35:229-239.

64. Sandstrom, E. G., J. S. Knapp, L. B. Reller, S. E. Thompson, E. W. Hook III, and K. K. Holmes. 1984. Serogrouping of Neisseria gonorrhoeae: correlation of serogroup with disseminated gonococcal infection. Sex. Transm. Dis. 11:77-80.

65. Sarafian, S. K., and J. S. Knapp. 1989. Molecular epidemiology of Neisseria gonorrhoeae. Clin. Microbiol. Rev. 2:(Suppl.)S49S55.

66. Sarafian, S. K., M. R., Tam, and S. A. Morse. 1983. Gonococcal protein I-specific opsonic IgG in normal human serum. J. Infect. Dis. 148:1025-1032.

67. Schalla, W. O., R. J. Rice, J. W. Biddle, Y. JeanLouis, S. A. Larsen, and W. L. Whittington. 1985. Lectin characterization of gonococci from an outbreak caused by penicillin-resistant Neisseria gonorrhocae. J. Clin. Microbiol. 22:481-483.

68. Schmitt, S., G. Layh, and T. M. Buchanan. 1986. Surfaceexposed antigenic cleavage fragments of Neisseria gonorrhoeae proteins IA and IB. Infect. Immun. 54:841-845.

69. Shafer, W. M., K. Joiner, L. F. Guymon, M. S. Cohen, and P. F. Sparling. 1984. Serum sensitivity of Neisseria gonorrhoeae: the role of lipopolysaccharide. J. Infect. Dis. 149:175-183.

70. Spratt, S. K., F. Jones, T. E. Shockley, and J. H. Jackson. 1980. Cotransformation of a serum resistance phenotype with genes for arginine biosynthesis in Neisseria gonorrhoeae. Infect. Immun. 29:287-289.

71. Stephens, D. S., and W. M. Shafer. 1987. Evidence that the serum resistance genetic locus sac-3 of Neisseria gonorrhoeae is involved in lipopolysaccharide structure. J. Gen. Microbiol. 133:2671-2678.

72. Swanson, J. 1980. Studies on gonococcus infection. XVIII. ${ }^{125}$ I-labeled peptide mapping of the major outer membrane protein of the gonococcal cell wall outer membrane. Infect. Immun. 23:799-810.

73. Swanson, J., and J. Heckels. 1980. Proposal: nomenclature of gonococcal outer membrane proteins, p. xxi. In D. Danielsson and S. Normark (ed.), Genetics and immunobiology of pathogenic Neisseria. University of Umeå, Umeå, Sweden.

74. Swanson, J., L. M. Mayer, and M. R. Tam. 1982. Antigenicity of Neisseria gonorrhoeae outer membrane protein(s) III detected by immunoprecipitation and Western blot transfer with monoclonal antibody. Infect. Immun. 38:668-672.

75. Tam, M. R., T. M. Buchanan, E. G. Sandstrom, K. K. Holmes, J. S. Knapp, A. W. Siak, and R. C. Nowinski. 1982. Serological classification of Neisseria gonorrhoeae with monoclonal antibodies. Infect. Immun. 36:1042-1053.

76. Teerlink, T., H. Versantvoort, and E. C. Beuvery. 1987. Antigenic and immunogenic properties of cyanogen bromide peptides from a serotype 5 gonococcal outer membrane protein I. 
Antonie Van Leeuwenhoek J. Microbiol. 53:493-499.

77. Virji, M., K. Zak, and J. E. Heckels. 1986. Monoclonal antibodies to gonococcal outer membrane protein IB: use in investigation of the potential protective effect of antibodies directed against conserved and type-specific epițopes. J. Gen. Microbiol. 132:1621-1629.

78. Young, J. D. E., M. Blake, A. Mauro, and Z. A. Cohn. 1983.
Properties of the major outer membrane protein from Neisseria gonorrhoeae incorporated into model lipid membranes. Proc. Natl. Acad. Sci. USA 80:3831-3835.

79. Zak, K., J. L. Diaz, D. Jackson, and J. E. Heckels. 1984 Antigenic variation during infection with Neisseria gonorrhoeae: detection of antibodies to surface proteins in sera of patients with gonorrhea. J. Infect. Dis. 149:166-174. 